\title{
Role of the G-Protein-Coupled Receptor GPR12 as High-Affinity Receptor for Sphingosylphosphorylcholine and Its Expression and Function in Brain Development
}

\author{
Atanas Ignatov, ${ }^{1 \star}$ Julia Lintzel, ${ }^{1 \star}$ Irm Hermans-Borgmeyer, ${ }^{1}$ Hans-Jürgen Kreienkamp, ${ }^{2}$ Patrick Joost, ${ }^{3}$ \\ Susanne Thomsen, ${ }^{3}$ Axel Methner, ${ }^{3}$ and H. Chica Schaller ${ }^{1}$ \\ ${ }^{1}$ Zentrum für Molekulare Neurobiologie Hamburg, ${ }^{2}$ Institut für Zellbiochemie und klinische Neurobiologie, and ${ }^{3}$ Klinik für Neurologie, Universität \\ Hamburg, D-20246 Hamburg, Germany
}

Lysophospholipids are bioactive molecules influencing numerous cellular processes such as proliferation, differentiation, and motility. As extracellular ligands, they interact with specific members of the G-protein-coupled receptor family. We show in this paper that the lysophospholipid sphingosylphosphorylcholine is a high-affinity ligand for the orphan G-protein-coupled receptor GPR12. Heterologous expression of GPR12 in Chinese hamster ovary cells and in frog oocytes revealed a high-affinity interaction with sphingosylphosphorylcholine in the nanomolar range. Blockade of its action by pertussis toxin was taken as evidence that GPR12 is coupled to an inhibitory G-protein. In the adult mouse brain, GPR12 was expressed in the limbic system. During mouse embryonal development, GPR12 transcripts were detected in the CNS, especially in areas where neuronal differentiation occurs. Consistent with this we found that cultures of embryonal cerebral cortical neurons responded to sphingosylphosphorylcholine with an increase in synaptic contacts. The GPR12expressing hippocampal cell line HT22 reacted to sphingosylphophorylcholine with an increase in cell proliferation and cell clustering. Other receptors known to interact at nanomolar concentrations with sphingosylphosphorycholine were expressed neither in the developing cerebral cortex nor in the HT22 cell line. We therefore hypothesize that sphingosylphosphorylcholine, most likely by interaction with GPR12, has positive effects on the differentiation and maturation of postmitotic neurons and that it may also influence the proliferation of neuronal precursor cells.

Key words: G-protein-coupled receptor; GPR12; lysophospholipid receptor; SPC; S1P; cerebral cortex development; HT22 cells

\section{Introduction}

G-protein-coupled receptors (GPCRs) are the largest family of cellsurface transmembrane proteins involved in signal transduction (Lefkowitz, 2000). They are activated by a wide variety of ligands, including ions, peptides, neuroamines, hormones, growth factors, odorants, and light. Recently lipids have been described as a new group of extracellular ligands for GPCRs, of which lysophospholipids play ever-increasing roles in nervous system signaling and brain development (Fukushima et al., 2001). The main lysophospholipids implied in such functions are lysophosphatidic acid (LPA), lysophosphatidylcholine (LPC), sphingosylphosphorylcholine (SPC), and sphingosine 1-phosphate (S1P).

The first high-affinity GPCR, described by Hecht et al. (1996) for the lysophospholipid LPA, is expressed in the murine developing cerebral cortex in the ventricular zone, where cell proliferation occurs, and was designated "ventricular zone gene-1". After the discovery of two additional LPA receptors, it was renamed

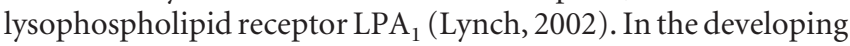
murine CNS, its expression in neurons starts at approximately

\footnotetext{
Received Aug. 13, 2002; revised 0ct. 21, 2002; accepted Nov. 8, 2002.

This work was supported by the Deutsche Forschungsgemeinschaft (Grants SFB 444, SFB 545, and GK 255). We thank GlaxoWellcome for providing us with the $\mathrm{CHO} / \mathrm{G} \alpha 16 / \mathrm{mtAEQ}$ cells, Günter Ellinghausen and Hans-Hinrich Hönck for excellent technical assistance, and I. Björn Riedel for help with the confocal analysis.

*A.I. and J.L. contributed equally to this work.

Correspondence should be addressed to H. Chica Schaller, Zentrum für Molekulare Neurobiologie, Universität Hamburg, Martinistrasse 52, 20246 Hamburg, Germany. E-mail: schaller@zmnh.uni-hamburg.de.

Copyright $\odot 2003$ Society for Neuroscience $\quad 0270-6474 / 03 / 230907-08 \$ 15.00 / 0$
}

embryonal day 11 (E11) and ends at E18, when cortical neurogenesis is completed. LPA is secreted by the differentiating neurons of the cortical plate and stimulates proliferation of neuroblasts in the ventricular zone (Fukushima et al., 2000). Another lysophospholipid that influences cell growth and cell migration is S1P, for which five members of the lysophospholipid receptor family exist (An et al., 1997; Lee et al., 1998; Van Brocklyn et al., 1998; Ancellin and Hla, 1999; Im et al., 2000). In addition to these receptors, four other GPCRs bind lysophospholipids: GPR4 and OGR1 are both high-affinity receptors for SPC, G2A binds LPC with high affinity, and for TDAG8 the glycolipid psychosine serves as ligand (Xu et al., 2000; Im et al., 2001; Kabarowski et al., 2001; Zhu et al., 2001). All four receptors control cell proliferation, either positively or negatively, depending on cell type and status of the cell.

To find a receptor for the neuropeptide head activator (Hampe et al., 1999), we constructed a novel phylogenetic tree that placed the orphan receptor GPR12 close to peptide and lipid receptors (Joost and Methner, 2002). We report in this paper that GPR12 is a high-affinity receptor for the lysophospholipid SPC and not for peptides. GPR12 is the only SPC receptor that is expressed predominantly in the embryonal and adult mouse brain. During cerebral cortical development, GPR12 is present in postmitotic neurons, suggesting a function for SPC in neuronal differentiation. In support of this notion, we found that primary cultures of cortical neurons express synaptic markers in the presence of SPC earlier, which may lead to an increase in synaptic 
contacts. Stimulation of cell proliferation of the hippocampal cell line HT22 hints at an additional function of SPC as growth factor.

\section{Materials and Methods}

Phylogenetic analysis. Two hundred thirty-five human family-A GPCR sequences obtained from SWISSPROT were aligned with CLUSTALX. An overall phylogenetic tree was inferred from the multiple sequence alignment excluding the $\mathrm{N}$ - and C-terminal ends with PHYLIP (Felsenstein, 1996). The dataset was bootstrapped 100 times to obtain support values for each internal branch. Pairwise distances were determined with PROTDIST using the JTT substitution frequency matrix, and neighborjoining phylogenetic trees were calculated with NEIGHBOR (Joost and Methner, 2002).

Full-length amplification and cloning of mouse GPR12 cDNA into mammalian and Xenopus expression vectors. Full-length cDNA of murine GPR12 was amplified by PCR from mouse genomic DNA using the gene-specific primers 5' ${ }^{\prime}$ TAAAATGACGAAGACCCGAAGG-3' and 5' CTATGAGGAGAAGGCTGCTACAC-3' for expression without signal peptide and $5^{\prime}$-GACAAGCGAATTCATGAAGGAAGACCGGA $3^{\prime}$ and 5'-ATACAATTCTAGACTGCTACACATCGCTG-3' for expression with a signal peptide. The GPR12 PCR product was subcloned into the pGEM-T-Easy vector (Promega, Heidelberg, Germany) and sequenced. Subsequently GPR12 was transferred into the EcoRI site of the mammalian expression vector pcDNA3, which does not contain a signal-peptide sequence, and into the EcoRI/XbaI sites of pSecTag, which harbors a signal-peptide sequence. Both vectors were from Invitrogen (Karlsruhe, Germany). For expression in Xenopus oocytes, GPR12 was transferred into the EcoRI-XbaI sites of the frog vector pGEMHE-SP without signalpeptide sequence (Liman et al., 1992) and from there into the HindIIIBamHI sites of pGEMHE + SP with signal-peptide sequence. All constructs were sequenced to ensure correct insertion and sequence.

Aequorin-based bioluminescent assay. CHO/G $\alpha 16 / \mathrm{mtAEQ}$ cells (Stables et al., 1997) were transiently transfected by electroporation with 10 $\mu \mathrm{g}$ of pcDNA3 or pSecTag into which nothing or GPR12 cDNA was cloned. Subsequently the cells were cultured in DMEM-F12 (Invitrogen)

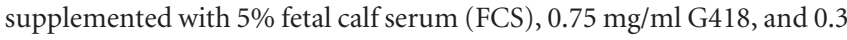
$\mathrm{mg} / \mathrm{ml}$ hygromycin for $24 \mathrm{hr}$ in 96-well plates, followed by $24 \mathrm{hr}$ in serum-free defined medium containing $5 \mu \mathrm{g} / \mathrm{ml}$ insulin, $30 \mu \mathrm{g} / \mathrm{ml}$ transferrin, $20 \mu \mathrm{M}$ ethanolamine, $30 \mathrm{~nm}$ sodium selenite, $1 \mu \mathrm{M}$ sodium pyruvate, $1 \%$ nonessential amino acids, and $1 \mathrm{~mm}$ glutamine. For $\mathrm{Ca}^{2+}$ measurements, cells were preincubated for $4 \mathrm{hr}$ in defined medium supplemented with $2.5 \mu \mathrm{M}$ coelenterazine (100 $\mu \mathrm{l}$ per well), before ligands were added in extracellular medium containing (in $\mathrm{mm}$ ): 125 $\mathrm{NaCl}, 5 \mathrm{KCl}, 2 \mathrm{MgCl}_{2}, 0.5 \mathrm{NaH}_{2} \mathrm{PO}_{4}, 5 \mathrm{NaHCO}_{3}, 10$ HEPES at $\mathrm{pH} 7.4,10$ glutamine, $0.1 \%$ bovine serum albumin. Luminescence was measured with a bioluminometer (Berthold Technologies, Bad Wildbad, Germany) at $37^{\circ} \mathrm{C}$ for $15 \mathrm{sec}$.

Expression in Xenopus oocytes. For functional expression in Xenopus oocytes, the GPR12 cRNA was in vitro transcribed from the pGEMHE+SP vector using T7-RNA-polymerase and a NheI-linearized plasmid and coinjected with GIRK1 (G-protein-gated inwardly rectifying $\mathrm{K}^{+}$channel) cRNA essentially as described previously (Bächner et al., 1999). For recording, oocytes were superfused with ND-96 medium containing (in mM): $96 \mathrm{NaCl}, 2 \mathrm{KCl}, 2.5 \mathrm{CaCl}_{2}, 1 \mathrm{MgSO}_{4}, 5$ HEPES, pH 7.5, and whole cells were clamped at $-60 \mathrm{mV}$. For agonist measurements the medium was changed to high $\mathrm{K}^{+}$medium (ND-96 with $96 \mathrm{mM} \mathrm{KCl}$ and $2 \mathrm{~mm} \mathrm{NaCl}$ ). After the initial inward current had reached a plateau, agonists were applied in the same medium. Agonist treatment was terminated by wash-out with high $\mathrm{K}^{+}$medium.

Lipids and peptide-enriched cell and tissue extracts. SPC and LPC were from Sigma-Aldrich (München, Germany); S1P and LPA were from Biomol (Hamburg, Germany) and represented the D-erythro-isomers of the respective lysophospholipids. L-erythro-SPC was from Matreya/ Biotrend (Köln, Germany). Peptide-enriched extracts were prepared as described previously (Kayser et al., 1998).

In situ hybridization. Fetal and neonatal mice from natural matings between inbred CD-1 mice (Charles River, Sulzfeld, Germany) were collected at the stages indicated. In situ hybridization on frozen sections was performed as described previously (Süsens et al., 1997). The animals were frozen on solid $\mathrm{CO}_{2}$, and $10 \mu \mathrm{m}$ sections were prepared on a cryostat. Adult mouse brains were sectioned at $15 \mu \mathrm{m}$. The $\left[{ }^{35} \mathrm{~S}\right]$-UTP-labeled sense and antisense probes encoded the entire GPR12 open reading frame. The hybridized sections were exposed to Kodak Biomax MR film for 3 d, dipped in Kodak NTB-2 nuclear emulsion (both from Amersham Biosciences, Freiburg, Germany), and exposed for $8 \mathrm{~d}$ to 3 weeks.

PCR amplification of GPR12, GPR4, and OGR1. Analysis of the transcript distribution of GPR12, GPR4, and OGR1 was performed by amplifying fragments with gene-specific primers common to mouse and man. For GPR12, a 690 base pair fragment was amplified with primers derived from positions 282-306 and 971-951 of the mouse sequence (GenBank accession NM_008151), for GPR4 a 769 base pair fragment was amplified with primers from positions $152-176$ and $920-896$ of the human sequence (GenBank accession U21051), and for OGR1 a 714 base pair fragment was amplified with primers from positions 112-136 and 828-805 of the human sequence (GenBank accession U48405). Templates amplified by PCR with platinum Taq were cDNAs from mouse HT22 cells and human placenta. Alternatively, total RNA from SH-SY5Y and rat primary embryonal cerebral cortical cells was amplified in the one-step Titan RT-PCR system (Roche Diagnostics, Mannheim, Germany) according to the manufacturer's instructions.

Cell culture and cell proliferation assays. The mouse hippocampal cell line HT22 was cultured in DMEM supplemented with 5\% FCS, 100 $\mathrm{IU} / \mathrm{ml}$ penicillin, $100 \mu \mathrm{g} / \mathrm{ml}$ streptomycin, and $10 \mathrm{~mm}$ HEPES, $\mathrm{pH}$ 7.2. To assay ligands, cells were kept overnight in serum-free defined medium. Cell proliferation was assayed by counting the number of cells in three dishes each by coulter counter (Coulter Electronics, Krefeld, Germany).

Primary cortical neurons were prepared from E15 rats. After dissociation of the brains in trypsin/EDTA, cells were seeded in $32 \mathrm{~mm}$ culture dishes in plating medium consisting of neurobasal medium with B-27 serum-free supplement (Invitrogen), $100 \mathrm{IU} / \mathrm{ml}$ penicillin, $100 \mu \mathrm{g} / \mathrm{ml}$ streptomycin, and $2 \mathrm{~mm}$ L-glutamine. Culture dishes and coverslips were precoated with $10 \mu \mathrm{g} / \mathrm{ml}$ poly-L-lysine and $10 \mu \mathrm{g} / \mathrm{ml}$ collagen $\mathrm{G}$ (both from Biochrom, Berlin, Germany). Cell numbers were determined after a $1 \mathrm{~d}$ treatment with SPC by counting $3 \times 3$ fields of $\sim 200$ cells each on separate slides.

Western blotting and immunocytochemistry. For Western blots, sample buffer preheated to $100^{\circ} \mathrm{C}$ was added to the cell pellets of primary cortical cultures. Cells were dissociated by repeated syringe pipetting, incubated for 5 min at $95^{\circ} \mathrm{C}$, and separated by SDS-PAGE. After semidry blotting, the filters were immunoreacted with monoclonal antibodies against synaptophysin (1:2000; Chemicon, Hofheim, Germany) and with polyclonal antisera against neurofilament H (1:500; Serotec, Düsseldorf, Germany) and visualized by enhanced chemiluminescence (Amersham Biosciences).

For immunocytochemistry, cerebral cortical neurons $(125,000)$ were seeded on $10 \mathrm{~mm}$ slides, fixed with $4 \%$ paraformaldehyde, permeabilized by ethanol, and preabsorbed with PBS containing $10 \%$ horse serum and $0.2 \%$ bovine serum albumin. They were then incubated with monoclonal antibodies against synaptophysin (1:2000) and visualized with Alexa Fluor 488 (MoBiTec, Göttingen, Germany).

\section{Results}

Sphingosylphosphorylcholine is a high-affinity ligand for the orphan G-protein-coupled receptor GPR12

A phylogenetic analysis of 235 human family-A GPCRs (Joost and Methner, 2002) placed the orphan subfamily consisting of GPR12, GPR6, and GPR3 in close proximity to the melanocortinlike peptide-receptor family and also to phospholipid and cannabinoid receptors (Fig. 1). This hinted at peptides or lipids as possible endogenous ligands.

For heterologous expression of GPR12, full-length cDNA was obtained by PCR using mouse genomic DNA as template. The PCR product was subcloned with and without a signal-peptide sequence into mammalian expression vectors. The inclusion of a signal peptide was chosen to improve membrane insertion, folding, and cell-surface expression (Guan et al., 1992; Kochl et al., 2002). For ligand screening we used a bioluminescent assay, 


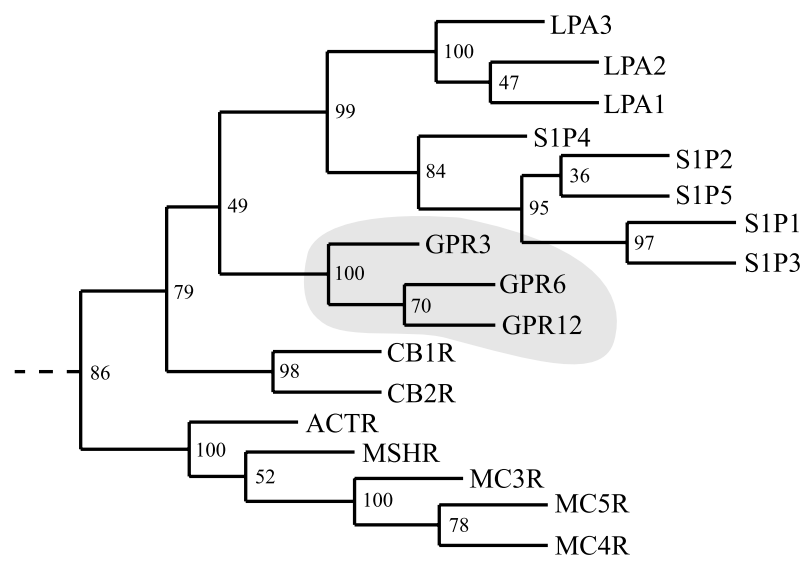

Figure 1. Section of an unrooted phylogenetic tree of human GPCRs. Numbers correspond to support values for each internal branch and were obtained by 100 bootstrap steps. Shaded receptors constitute a subfamily located between cannabinoid (CBR), lysophospholipid (LPA) $S T P)$, and the proopiomelanocortin peptide receptors (MCR, MSHR, ACTR).

which had proven successful in other laboratories (Stables et al., 1997), namely Chinese hamster ovary cells, stably transfected with the mitochondrially targeted apoaequorin as $\mathrm{Ca}^{2+}$ sensor and the promiscuous $\mathrm{G}$-protein subunit $\mathrm{G}_{\alpha 16}$ to improve signal transduction $(\mathrm{CHO} / \mathrm{G} \alpha 16 / \mathrm{mtAEQ})$. After reconstitution with the aequorin cofactor coelenterazine, agonist action was monitored as increase in $\mathrm{Ca}^{2+}$ luminescence. This assay is applicable also for GPCRs, which are not physiologically coupled to the release of $\mathrm{Ca}^{2+}$ from intracellular stores. We found that SPC evoked a significant increase in $\mathrm{Ca}^{2}$-induced luminescence if such $\mathrm{CHO}$ cells were transiently transfected with GPR12 containing a signal-peptide sequence. $\mathrm{CHO}$ cells transfected with vector alone or with GPR12 without signal-peptide sequence showed only basal $\mathrm{Ca}^{2+}$ levels (Fig. $2 \mathrm{~A}$ ). This indicates that no endogenous SPC receptors are present in CHO cells and that SPC reacts with GPR12 only, if heterologously expressed in a vector containing a signal-peptide sequence. Therefore, all subsequent experiments were performed with this construct. The binding of SPC to GPR12 was stereospecific: the physiologically relevant D-isomer of SPC, D-erythro-SPC, bound with a 10-fold higher affinity than the L-isomer, L-erythro-SPC (Fig. 2 B). To assay specificity of SPC as ligand, we also tested related lysophospholipids such as S1P, LPA, and LPC for their effect on GPR12. S1P and LPA already responded with vector-transfected $\mathrm{CHO}$ cells, indicating the presence of endogenous receptors. S1P showed a small increase and LPA showed no increase over this endogenous response (Fig. 2C). The relative light response for endogenous receptors was higher because of the fact that all cells responded and not only the transfected ones, the transfection efficiencies of which varied between 20 and $30 \%$. LPC was without effect on $\mathrm{CHO}$ cells transfected with vector or with GPR12. A doseresponse curve, for which the basal and endogenous light units were subtracted, yielded an $\mathrm{EC}_{50}$ value of $66 \mathrm{~nm}$ for SPC and $1.2 \mu \mathrm{M}$ for S1P. LPC and LPA were without effect at the concentrations assayed (Fig. 2D).

To confirm these data and the specificity of the ligands, we used a second independent assay system, which had also proven successful for deorphanizing GPCRs (Bächner et al., 1999). In this assay, ligands are analyzed for their effect on $\mathrm{K}^{+}$currents in Xenopus oocytes. For this purpose, cRNA from the GPCR under investigation is coinjected with cRNA coding for the G-protein gated inwardly rectifying $\mathrm{K}^{+}$channel (GIRK), the latter to im-
A

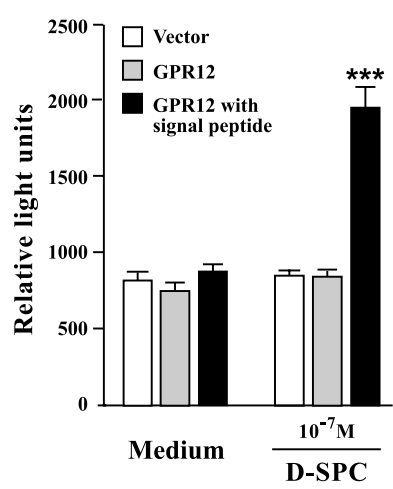

B

C

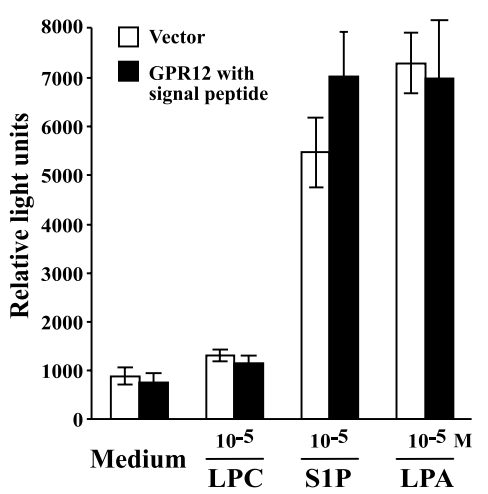

D

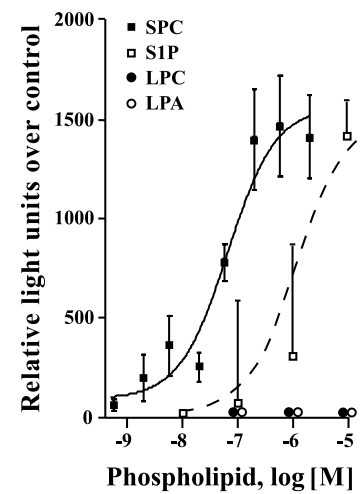

Figure 2. SPC is a high-affinity ligand for GPR12. $A, \mathrm{CH} 0 / \mathrm{G} \alpha 16 / \mathrm{mt} A E \mathrm{Q}$ cells were transiently transfected with the vector as control, with GPR12 without and with a signal-peptide sequence. Cells were treated with medium alone or with medium containing $100 \mathrm{~nm}$ D-SPC, and the $\mathrm{Ca}^{2+}$-bioluminescent response was measured at $469 \mathrm{~nm}$. SPC induced a significant increase in luminescence in cells transfected with GPR12 with signal peptide compared with vector controls and cells transfected with GPR12 without signal peptide $(* * * p<0.001)$. GPR12 constructs with a signal-peptide sequence were used subsequently. $B$, The $\mathrm{Ca}^{2+}$-bioluminescence response was monitored after treatment with $\mathrm{D}$ and $\mathrm{L}$ stereoisomers of SPC. The increase of $10^{-7}$ $M$ and $10^{-6} \mathrm{M} \mathrm{D-SPC}$ over the medium control was significant $\left({ }^{* * *} p<0.001\right)$. C, Other lysophospholipids were assayed at the indicated concentrations. LPC and LPA did not elicit $\mathrm{Ca}^{2+}$ responses, but S1P did. Each bar graph in $A-C$ represents the means of six determinations \pm SEM. D, Dose-response curves, from which the endogenous responses were subtracted, yielded an $\mathrm{EC}_{50}$ value of $66 \mathrm{~nm}$ for SPC and $1.2 \mu \mathrm{m}$ for S1P. LPA and LPC were assayed in the same concentration range but did not show any response.

prove current detection. SPC induced a strong GIRK-mediated inward current in oocytes expressing GPR12. No response was detected in control oocytes injected with GIRK cRNA alone (Fig. $3 A)$. Xenopus oocytes expressing GPR12 also responded to S1P, albeit with a weaker inward current compared with SPC. Doseresponse curves revealed an $\mathrm{EC}_{50}$ value of $32 \mathrm{~nm}$ for $\mathrm{SPC}$ and 3.1 $\mu \mathrm{M}$ for S1P (Fig. 3B). The activation of GIRK currents in the Xenopus oocyte system was suggestive of a signal-transduction pathway coupled to an inhibitory G-protein. Because high concentrations of SPC or S1P were not able to activate $\mathrm{Ca}^{2+}$-induced $\mathrm{Cl}^{-}$currents, we excluded $\mathrm{G}_{\mathrm{q}}$ as $\alpha$ subunit. In addition, SPC- and S1P-induced GIRK currents were abolished in oocytes pretreated with pertussis toxin, confirming the notion that signal transduction is mediated by $\mathrm{G}_{\mathrm{i}}$ or $\mathrm{G}_{\mathrm{o}}$ (Fig. 3C).

In both assay systems, peptides and peptide extracts from rat brains and neuronal cell lines did not evoke responses. In summary, these data show that GPR12 is a high-affinity receptor for 
A

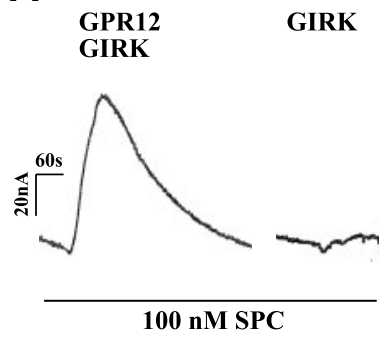

B

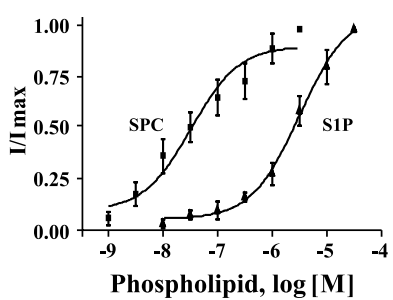

C

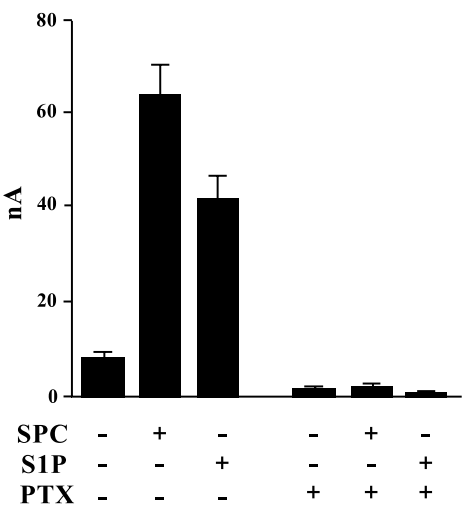

Figure 3. $S P C$ is a high-affinity and S1P is a low-affinity ligand for GPR12 expressed in frog oocytes. A, Currents induced by $100 \mathrm{~nm} \mathrm{SPC}$ were recorded from Xenopus 0ocytes injected with cRNAs coding for GPR12 with signal peptide and for GIRK, or with GIRK CRNA alone. B, Doseresponse curves for SPC- and S1P-induced increases in GIRK-mediated inward currents were normalized against maximum currents obtained for each oocyte. Seven oocytes were measured independently for each agonist. The dose-response data were subjected to nonlinear regression analysis using the GraphPad Prism software. C, SPC-induced (100 nM) and S1P-induced (1 $\mu \mathrm{M})$ GIRK currents were measured with and without a $12 \mathrm{hr}$ pretreatment of oocytes with 200 $\mathrm{ng} / \mathrm{ml}$ of pertussis toxin (PTX).

SPC and a low-affinity receptor for S1P, independent of the expression system used.

\section{Expression of GPR12 during embryonal development and in} the adult brain

GPR12 was originally isolated from rat and mouse brain cDNA libraries and a human homolog from genomic DNA (Saeki et al., 1993; Song et al., 1994, 1995). To get insight into a possible role of GPR12 in brain development, we performed in situ hybridizations on sections of embryonal mice. High signal intensities of GPR12 mRNA were detected in all areas of the developing CNS starting from E14.5 (Fig. 4A). The cerebral cortex showed more intense labeling than other brain areas. At E16.5 the hybridization signals of GPR12 in the cerebral cortex and the hippocampus increased, whereas those in the brain stem and the spinal cord started to decline. At E16.5 transcripts were also detected in the
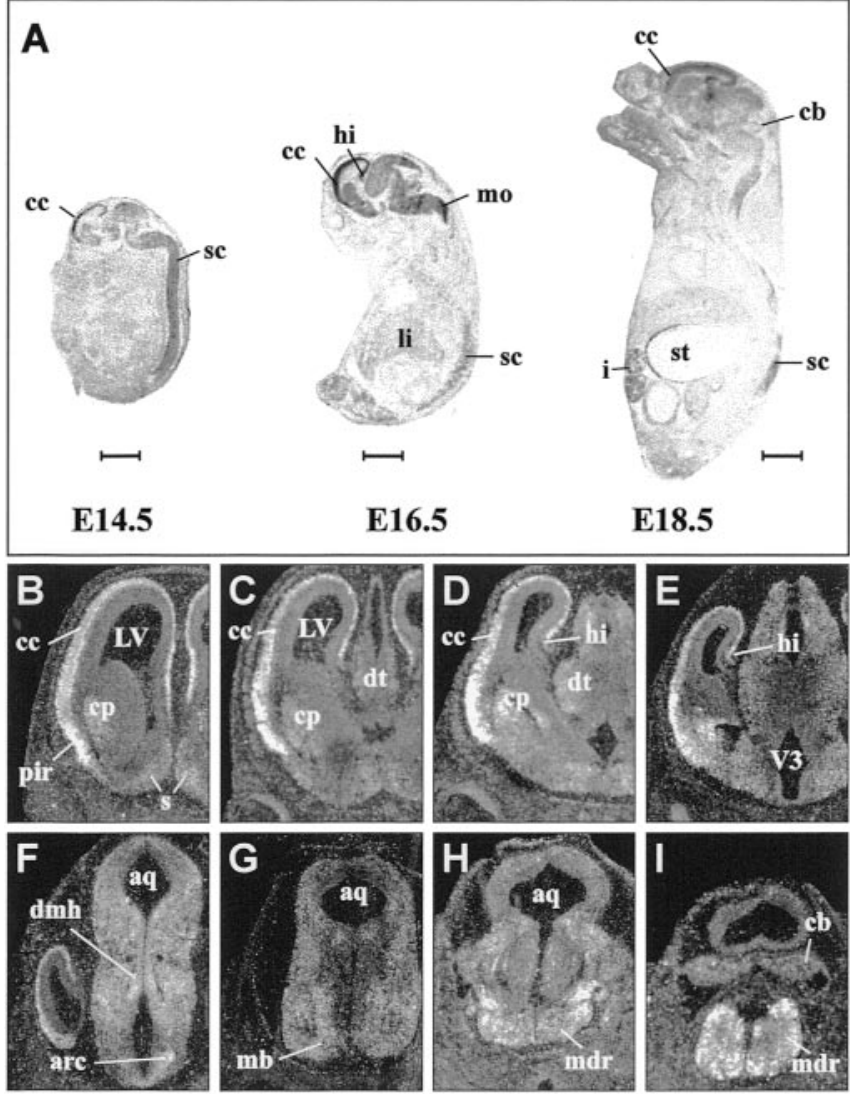

Figure 4. Expression of GPR12 during mouse embryogenesis and in the developing nervous system. $A$, Autoradiograms of parasagittal sections through mouse embryos are shown at the stages indicated. Scale bars, $2 \mathrm{~mm}$. B-I, Photoemulsion-dipped coronal sections through a mouse brain at E14.5 are arranged in rostral to caudal direction. aq, Aqueduct; arc, arcuate hypothalamic nucleus; $c b$, cerebellum; $c c$, cerebral cortex; $c p$, caudate putamen; $d m h$, dorsomedial hypothalamic nucleus; $d t$, dorsal thalamus; $h i$, hippocampus; $i$, intestine; $L V$, lateral ventricle; li, liver; $m b$, mammillary body; $m d r$, medullary reticular formation; $m o$, medulla oblongata; pir, piriform cortex; $s$, septum; sc, spinal cord; st, stomach; $t$, thalamus; V3, third ventricle.

liver and $2 \mathrm{~d}$ later in the intestine and the stomach, albeit at lower levels than in the CNS.

To investigate the distribution of the GPR12 transcripts in the embryonal brain in more detail, we performed in situ hybridization on frozen sections of mouse brain at E14.5. Analysis of emulsion-dipped sections revealed strong signals over the cortical plate, the piriform cortex, and the hippocampus (Fig. $4 B-E$ ). Signals were also detected in the dorsomedial and arcuate nuclei (Fig. $4 F$ ), and weaker ones were detected in the mammillary body (Fig. 4G). Motoric and sensoric nuclei of the hindbrain in the medullary reticular formation were intensely labeled (Fig. 4H,I). GPR12 transcripts were also present in the caudate putamen, which begins to differentiate at E14.5 (Fig. $4 B-D$ ). In general, transcripts were abundant in regions of neuronal differentiation, whereas they were absent from areas of neuroblast proliferation such as the ventricular zones.

In the mature brain, heavily labeled cells were restricted to the somatosensory (Fig. 5C-E) and retrosplenial cortex (Fig. $5 H$ ). In the hippocampus (Fig. $5 F, G$ ), the overall signal intensity was high, but the pyramidal cells of the CA2 region were more intensely labeled than the granular cells of the dentate gyrus and the pyramidal cells in the CA1 and CA3 fields (Fig. $5 J, K$ ). The nucleus accumbens (Fig. $5 B$ ), the piriform cortex (Fig. $5 B-E$ ), the septum (Fig. $5 D, E$ ), and the hippocampus were highlighted by 

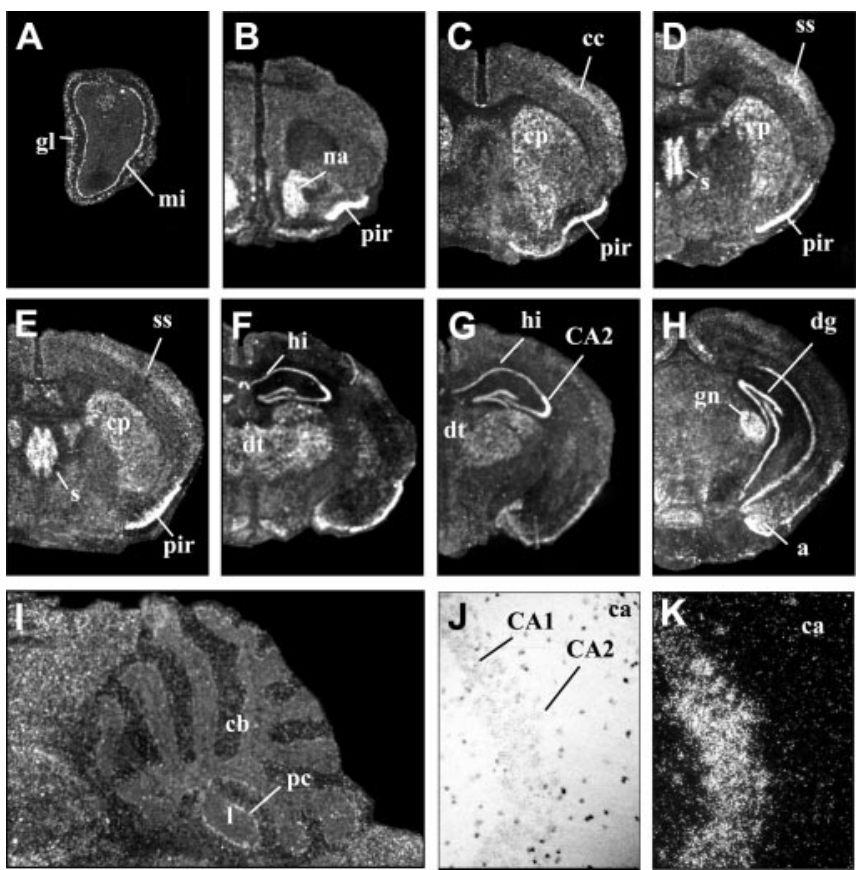

Figure 5. Expression of GPR12 in distinct areas of the adult CNS. A-I, Dark-field photomicrographs of photoemulsion-dipped coronal sections through an adult mouse forebrain and midbrain and a sagittal section (I) through the cerebellum are shown arranged in rostral to caudal direction. $J, K$, A higher magnification of the hippocampus is shown as a bright-field $(J)$ and a dark-field picture $(K)$, depicting the intense hybridization signals arising from the pyramidal cells of the $C A 2$ region. $a$, Amygdala; $C A 1$, CA1 layer of the hippocampus; $C A 2$, CA2 layer of hippocampus; $c a$, corpus callosum; $c b$, cerebellum; $c c$, cerebral cortex; $c p$, caudate putamen; $d g$, dentate gyrus; $d t$, dorsal thalamus; $g l$, glomerular layer of olfactory bulb; $g n$, geniculate nucleus; hi, hippocampus; I, cerebellar lobule; mi, mitral cell layer of olfactory bulb; na, nucleus acumbens; pir, piriform cortex; $p c$, Purkinje cell layer; s, septum; ss, somatosensory cortex.

hybridization signals. The mitral and glomerular cell layers of the olfactory bulb (Fig. 5A), the amygdala (Fig. $5 \mathrm{H}$ ), and the geniculate nucleus (Fig. $5 H$ ) were also intensely labeled. In the hindbrain area, signals were weak, and only some of the Purkinje cells of the cerebellum, located in lobules 9 and 10, exhibited signals above background (Fig. 5I). Fiber tracts, as for example in the corpus callosum (Fig. 5C-G,J,K), did not exhibit hybridization signals over background, and labeled cells showed neuronal characteristics pointing to a neuronal localization of GPR12 (Fig. $5 J, K$ ).

\section{Possible functions of SPC and GPR12 in neuronal development}

SPC is a high-affinity ligand not only for GPR12 but also for GPR4 and OGR1, both of which are expressed predominantly in peripheral organs and tissues (Xu et al., 2000; Zhu et al., 2001). To be sure that we measured the effects of SPC on GPR12 alone, we analyzed neuronal cell lines and primary cultures of embryonal cerebral cortical cells for the presence of the three receptor RNAs by PCR. We found that GPR4 and OGR1 were not expressed in any of the neuronal cell lines and primary neuronal cultures that were investigated. Even after 60 PCR cycles, no message was amplified. As control we used placenta cDNA, from which GPR4, OGR1, and GPR12 messages were readily amplified after 30 cycles (Fig. 6). GPR12 RNA was present in cerebral cortex tissue from E18 rats and in the mouse hippocampal cell line HT22. In each case, 30 cycles sufficed to reveal its presence. No GPR12 message was found in the neuroblastoma cell line SH-SY5Y (Fig. 6).

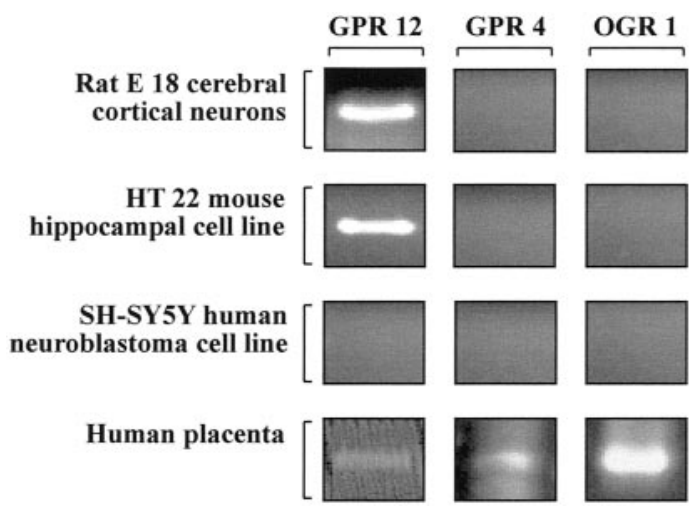

Figure 6. Presence of the SPC receptors GPR12, GPR4, and OGR1 in neuronal cells. The expression of RNA for the three receptors was probed by RT-PCR with primers common in mouse and human to amplify fragments of comparable lengths: 690 base pairs for GPR12, 769 base pairs for GPR4, and 714 base pairs for OGR1. If no product was obtained after 30 cycles, an aliquot was subjected to a second round of $P C R$.

Because the in situ data had revealed a high expression of GPR12 in the hippocampus, both in the mature brain and during embryonal development, the hippocampal cell line HT22, which expressed GPR12 only and not the other SPC receptors, was of special interest for a first analysis of SPC function in the nervous system. HT22 cells responded to SPC with an increase in cell number over untreated controls starting from nanomolar concentrations of SPC, and this effect was stereospecific (Fig. 7A). At concentrations of SPC higher than $1 \mu \mathrm{M}$, cells appeared to cluster (Fig. 7B), which could be caused either by a different coupling pathway or by interaction with a yet unknown low-affinity receptor. SPC had no effect on SH-SY5Y cells (data not shown).

In the embryonal cerebral cortex, GPR12 was expressed prominently in the developing cortical plate, which contains differentiating postmitotic neurons. To study SPC function in the cerebral cortex, primary rat cortical cultures were established at E15. Brain tissue was dissociated into cells, and after $1 \mathrm{~d}$ in culture, SPC was added. Protein extracts were probed with antibodies against synaptophysin and neurofilament $\mathrm{H}$ as markers for neuronal differentiation. No change in neurofilament $\mathrm{H}$ immunoreactivity was observed in response to SPC. A stimulation of synaptophysin production occurred after SPC treatment and time in culture (Fig. 8A). This was not attributable to increased cell proliferation and cell survival in SPC-treated cultures (Fig. $8 B$ ), hinting at a role of SPC in synapse formation. To measure synaptic contacts, cells were immunostained with antibodies against synaptophysin. After 1, 3, and $5 \mathrm{~d}$ of treatment with SPC, more synaptophysin-positive boutons and connections were present along dendrites on SPC-treated than on control neurons (Fig. 8C).

\section{Discussion}

Our results demonstrate that SPC is a high-affinity ligand for the orphan receptor GPR12. S1P also bound to GPR12, albeit with 100 -fold reduced potency and efficacy. The respective $\mathrm{EC}_{50}$ values after heterologous expression in the frog oocyte system were $32 \mathrm{~nm}$ and $3.1 \mu \mathrm{M}$, respectively. The $\mathrm{EC}_{50}$ of $32 \mathrm{~nm}$ for SPC is in good agreement with the $K_{\mathrm{d}}$ values of 36 and $33 \mathrm{~nm}$ found for the other two G-protein-coupled SPC receptors, GPR4 and OGR1, respectively (Xu et al., 2000; Zhu et al., 2001). We succeeded in deorphanizing GPR12 based on two paradigms. We created a new phylogenetic tree of 235 human family-A GPCRs, which placed GPR12 and its related orphan receptors GPR3 and GPR6 
A

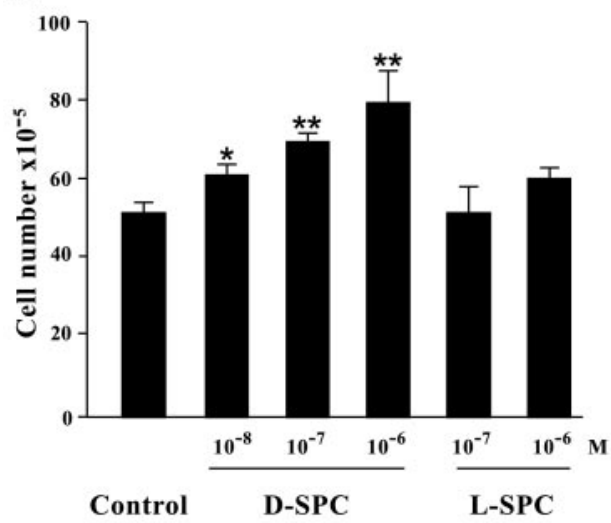

B

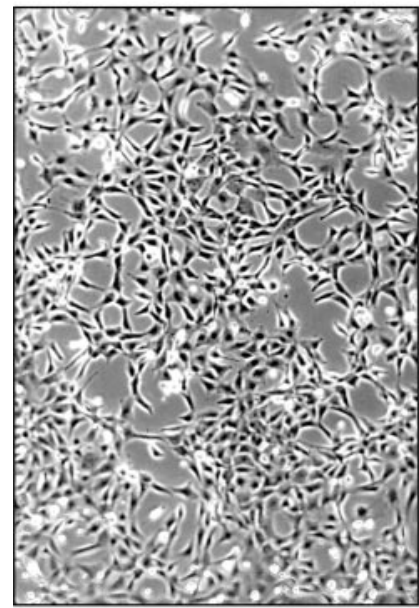

Control

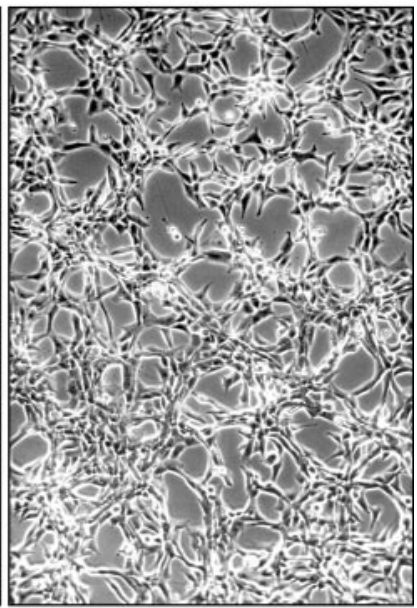

$3 \mu \mathrm{M} \mathrm{SPC}$
Figure 7. SPC stimulates cell proliferation and cell clustering in the hippocampal cell line HT22, and this response is stereospecific. A, HT22 cells were incubated for $3 \mathrm{~d}$ with the $D$ and $L$ stereoisomers of SPC at the indicated concentrations. The cell number was determined by coulter counter. Three dishes were counted each, and the cell number is expressed as mean \pm SEM $\left({ }^{*} p<0.05 ;{ }^{* *} p<0.01\right)$. B, HT22 cells were treated for $4 \mathrm{~d}$ with increasing concentrations of SPC. Cell clustering is shown for cells treated with $3 \mu \mathrm{M} S P C$ and compared with untreated controls.

in close proximity not only to peptide but also to lipid receptors (Joost and Methner, 2002), and we improved heterologous surface expression of GPR12 by including a signal sequence. This had proven effective for other GPCRs (Guan et al., 1992; Kochl et al., 2002). Only GPR12 with a signal-peptide sequence responded to SPC. The effect of SPC on GPR12 was mediated by an inhibitory G-protein, as evidenced by its sensitivity to pertussis toxin. SPC acted in a stereospecific manner; the physiologically relevant D isomer mobilized $\mathrm{Ca}^{2+}$ from internal stores and stimulated cell proliferation 10 times better than the $\mathrm{L}$ isomer. This is in agreement with the notion that the action of SPC is mediated by a receptor at the plasma membrane and not by intracellular receptors, for which no stereospecificity was found (Chun et al., 1999).

Recently, homology and mutational analyses resulted in a model for the interaction of phospholipids with their receptors (Parrill et al., 2000; Wang et al., 2001). The S1P and LPA receptors $\mathrm{S}_{1} \mathrm{P}_{1-5}$ and $\mathrm{LPA}_{1-3}$ share two arginines in extracellular loops one and three, which ion pair with the phosphate of LPA and S1P. A glutamate residue in the first extracellular loop interacts with the ammonium moiety of S1P, whereas a glutamine allows hydrogen
A
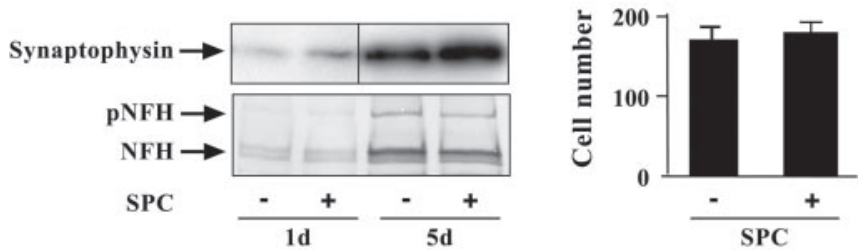

C
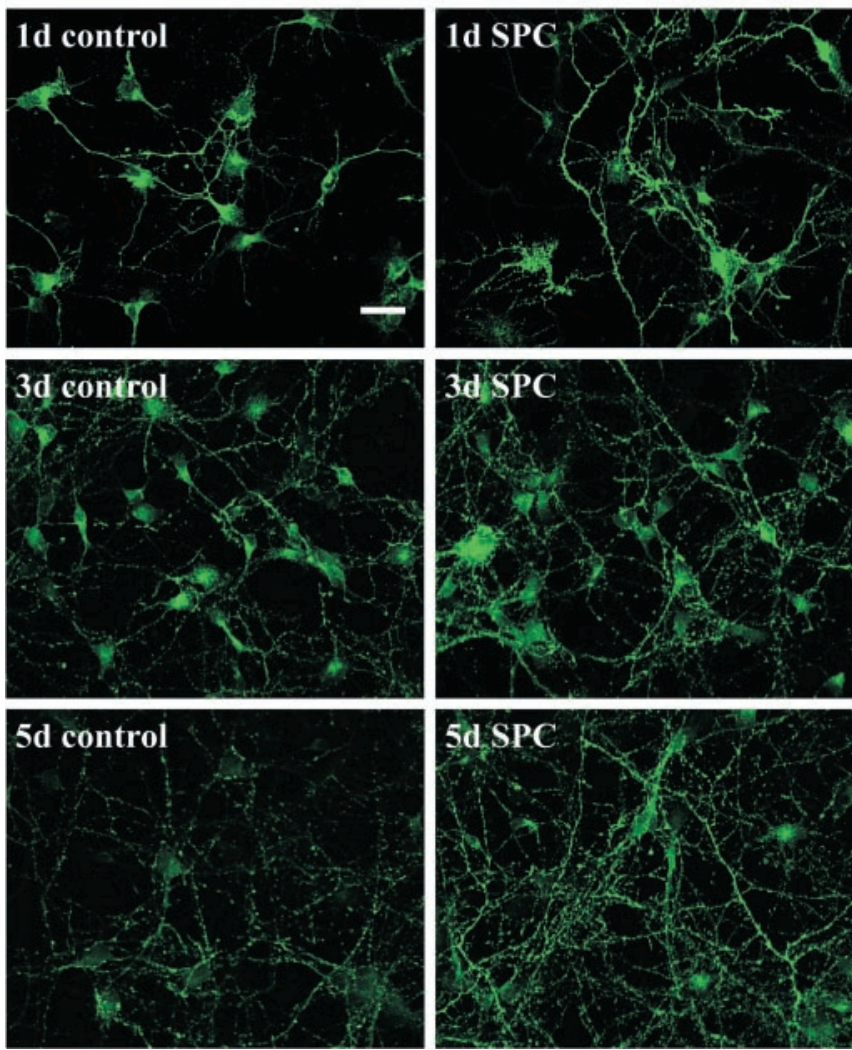

Figure 8. Primary cerebral cortical cultures of E15 rats respond to SPC by an increase in synaptic contacts. A, Western blots of extracts from cerebral cortical cultures treated for 1 and $5 \mathrm{~d}$ with $1 \mu \mathrm{m} S P C$ were probed with antisera against synaptophysin and neurofilament $H$. Equal amounts of protein were applied per lane. NFH represents the unphosphorylated immature 160 $\mathrm{kDa}$, and $p N F H$ represents the phosphorylated mature $185 \mathrm{kDa}$ form of neurofilament $H$. B, Total cell number was determined by counting three fields on three different slides after a $1 \mathrm{~d}$ treatment with SPC and is expressed as mean \pm SEM. C, An increase in synaptic contacts of cortical neurons treated for 1,3 , and $5 \mathrm{~d}$ with $1 \mu \mathrm{MSPC}$ was visualized by immunocytochemical staining with antisera against synaptophysin. Scale bar, $20 \mu \mathrm{m}$.

bonding with the hydroxyl group in LPA. In analogy, one would predict that in a receptor for SPC a basic and an acidic residue also should be present to ion pair with the ammonium and the phosphate, whereas an additional acid residue may be required to interact with the choline base. GPR12 and the other known highaffinity receptors for SPC have no arginine-glutamate signature in their first extracellular loop, but they do have basic and acidic amino acids in their second extracellular loop and additional acidic amino acids in their third extracellular loop. It is tempting to speculate that these amino acids play similar roles in forming a ligand-binding pocket as in the S1P and LPA receptors.

The similarity in structure of SPC with S1P explains why SPC can bind to the $\mathrm{S} 1 \mathrm{P}$ receptors $\mathrm{S}_{1} \mathrm{P}_{1-5}$, and vice versa why $\mathrm{S} 1 \mathrm{P}$ 
interacts with GPR12, although in both instances with a $\sim 100$ fold lower efficiency. GPR 12 shares only $24 \%$ sequence identity with OGR 1 and GPR4, $34 \%$ with $\mathrm{S}_{1} \mathrm{P}_{5}$, but $57 \%$ and $58 \%$ with the orphan receptors GPR3 and GPR6, respectively. This establishes GPR3, GPR6, and GPR12 as a distinct family, which may share structural features with $\mathrm{S}_{1} \mathrm{P}_{5}$ but ligand-binding properties with OGR1 and GPR4.

In situ hybridization analysis revealed that GPR12 is expressed in distinct locations of the adult murine brain, as described for several members of the lysophospholipid-receptor family. Prominent hybridization signals were detected in the forebrain region, where major constituents of the limbic system were labeled, suggesting an involvement of GPR12 and its ligand in the control of a diverse set of behavioral functions. A special feature of GPR 12 is its predominant expression in the CA2 field of the hippocampus, an area that is known for its resistance to epileptic seizures and its high content of the calcium binding protein parvalbumin. During embryonal development, GPR12 is expressed in a dynamic manner predominantly in the developing CNS. First, hybridization signals were detected at E14.5, when neurons start to migrate and differentiate. Consistent with this observation, we did not observe labeling over the ventricular zone, where proliferation of neuronal precursors takes place. In many regions of the brain expression was transient, as for example in the cerebral cortex, where the high labeling intensity coincided with the main phase of layer formation and neuronal differentiation.

To test endogenous function, we chose to work with the murine hippocampal cell line HT22 and with embryonal cerebral cortical neurons, because both expressed GPR12 but did not contain GPR4 and OGR1. SPC stimulated cell proliferation in HT22 cells starting from nanomolar concentrations. Treatment of primary cultures of rat cerebral cortical neurons with SPC led to an increase in immunoreactivity of synaptophysin in Western blots. This could be confirmed by visualizing synaptogenesis in immunocytochemical preparations with antibodies against synaptophysin, which marked areas rich in synaptic boutons. Synaptic contacts were visible earlier and at higher density in the presence of SPC. Neurofilament $\mathrm{H}$, which is a marker for axonal differentiation, was unchanged by SPC.

The other lysophospholipid important during early cortical development is LPA. It stimulates cell proliferation of cortical neuroblasts located in the ventricular zone of the cerebral cortex, and it inhibits neuronal differentiation in the cortical plate (Fukushima et al., 2001). Because postmitotic neurons produce LPA, a reciprocal control mechanism may regulate cell proliferation, dendritic outgrowth, and differentiation in these two cortical layers. Additional functions are suggested by the presence of GPR12 in the adult CNS, where SPC may have a role in maintaining synaptic stability. Stimulation of synaptophysin production, which was recently shown to regulate activity-dependent synapse formation in hippocampal neurons (Tarsa and Goda, 2002), may hint at a role for SPC and GPR12 in memory consolidation.

\section{References}

An S, Bleu T, Huang W, Hallmark OG, Coughlin SR, Goetzl EJ (1997) Identification of cDNAs encoding two $G$ protein-coupled receptors for lysosphingolipids. FEBS Lett 417:279-282.

Ancellin N, Hla T (1999) Differential pharmacological properties and signal transduction of the sphingosine 1-phosphate receptors EDG-1, EDG-3, and EDG-5. J Biol Chem 274:18997-19002.
Bächner D, Kreienkamp HJ, Weise C, Buck F, Richter D (1999) Identification of the melanin concentrating hormone $(\mathrm{MCH})$ as the natural ligand for the orphan somatostatin-like receptor 1 (SLC-1). FEBS Lett 457:522-524.

Chun J, Contos JJ, Munroe D (1999) A growing family of receptor genes for lysophosphatidic acid (LPA) and other lysophospholipids (LPs). Cell Biochem Biophys 30:213-242.

Felsenstein J (1996) Inferring phylogenies from protein sequences by parsimony, distance, and likelihood methods. Methods Enzymol 266:418-427.

Fukushima N, Weiner JA, Chun J (2000) Lysophosphatidic acid (LPA) is a novel extracellular regulator of cortical neuroblast morphology. Dev Biol 228:6-18

Fukushima N, Ishii I, Contos JJ, Weiner JA, Chun J (2001) Lysophospholipid receptors. Annu Rev Pharmacol Toxicol 41:507-534.

Guan XM, Kobilka TS, Kobilka BK (1992) Enhancement of membrane insertion and function in a type IIIb membrane protein following introduction of a cleavable signal peptide. J Biol Chem 267: 21995-21998.

Hampe W, Hermans-Borgmeyer I, Schaller HC (1999) Function of the neuropeptide head activator for early neural and neuroendocrine development. In: Regulatory peptides and their cognate receptors (Richter D, ed), pp 323-337. Berlin: Springer.

Hecht JH, Weiner JA, Post SR, Chun J (1996) Ventricular zone gene-1 (vzg-1) encodes a lysophosphatidic acid receptor expressed in neurogenic regions of the developing cerebral cortex. J Cell Biol 135:1071-1083.

Im DS, Heise CE, Ancellin N, O’Dowd BF, Shei GJ, Heavens RP, Rigby MR, Hla T, Mandala S, McAllister G, George SR, Lynch KR (2000) Characterization of a novel sphingosine 1-phosphate receptor, Edg-8. J Biol Chem 275:14281-14286.

Im DS, Heise CE, Nguyen T, O’Dowd BF, Lynch KR (2001) Identification of a molecular target of psychosine and its role in globoid cell formation. J Cell Biol 153:429-434.

Joost P, Methner A (2002) Phylogenetic analysis of 277 human G-proteincoupled receptors as a tool for the prediction of orphan receptor ligands. Genome Biol 3:0063.

Kabarowski JH, Zhu K, Le LQ, Witte ON, Xu Y (2001) Lysophosphatidylcholine as a ligand for the immunoregulatory receptor G2A. Science 293:702-705.

Kayser ST, Ulrich H, Schaller HC (1998) Involvement of a Gardos-type potassium channel in head activator-induced mitosis of BON cells. Eur J Cell Biol 76:119-124.

Kochl R, Alken M, Rutz C, Krause G, Oksche A, Rosenthal W, Schulein R (2002) The signal peptide of the $G$ protein-coupled human endothelin B receptor is necessary for translocation of the N-terminal tail across the endoplasmic reticulum membrane. J Biol Chem 277:16131-16138.

Lee MJ, Van Brocklyn JR, Thangada S, Liu CH, Hand AR, Menzeleev R, Spiegel S, Hla T (1998) Sphingosine-1-phosphate as a ligand for the G protein-coupled receptor EDG-1. Science 279:1552-1555.

Lefkowitz RJ (2000) The superfamily of heptahelical receptors. Nat Cell Biol 2:133-136.

Liman ER, Tytgat J, Hess P (1992) SubU stoichiometry of a mammalian K+ channel determined by construction of multimeric cDNAs. Neuron 9:861-871.

Lynch KR (2002) Lysophospholipid receptor nomenclature. Biochim Biophys Acta 1582:70-71.

Parrill AL, Wang D, Bautista DL, Van Brocklyn JR, Lorincz Z, Fischer DJ, Baker DL, Liliom K, Spiegel S, Tigyi G (2000) Identification of Edg1 receptor residues that recognize sphingosine 1-phosphate. J Biol Chem 275:39379-39384.

Saeki Y, Ueno S, Mizuno R, Nishimura T, Fujimura H, Nagai Y, Yanagihara T (1993) Molecular cloning of a novel putative $G$ protein-coupled receptor (GPCR21) which is expressed predominantly in mouse central nervous system. FEBS Lett 336:317-322.

Song ZH, Young III WS, Brownstein MJ, Bonner TI (1994) Molecular cloning of a novel candidate $\mathrm{G}$ protein-coupled receptor from rat brain. FEBS Lett 351:375-379.

Song ZH, Modi W, Bonner TI (1995) Molecular cloning and chromosomal localization of human genes encoding three closely related G proteincoupled receptors. Genomics 28:347-349. 
Stables J, Green A, Marshall F, Fraser N, Knight E, Sautel M, Milligan G, Lee M, Rees S (1997) A bioluminescent assay for agonist activity at potentially any G-protein-coupled receptor. Anal Biochem 252:115-126.

Süsens U, Aguiluz JB, Evans RM, Borgmeyer U (1997) The germ cell nuclear factor mGCNF is expressed in the developing nervous system. Dev Neurosci 19:410-420

Tarsa L, Goda Y (2002) Synaptophysin regulates activity-dependent synapse formation in cultured hippocampal neurons. Proc Natl Acad Sci USA 99:1012-1016.

Van Brocklyn JR, Lee MJ, Menzeleev R, Olivera A, Edsall L, Cuvillier O, Thomas DM, Coopman PJ, Thangada S, Liu CH, Hla T, Spiegel S (1998) Dual actions of sphingosine-1-phosphate: extracellular through the
Gi-coupled receptor Edg-1 and intracellular to regulate proliferation and survival. J Cell Biol 142:229-240.

Wang DA, Lorincz Z, Bautista DL, Liliom K, Tigyi G, Parrill AL (2001) A single amino acid determines lysophospholipid specificity of the S1P1 (EDG1) and LPA1 (EDG2) phospholipid growth factor receptors. J Biol Chem 276:49213-49220.

Xu Y, Zhu K, Hong G, Wu W, Baudhuin LM, Xiao Y, Damron SD (2000) Sphingosylphosphorylcholine is a ligand for ovarian cancer G-proteincoupled receptor 1. Nat Cell Biol 2:261-267.

Zhu K, Baudhuin LM, Hong G, Williams FS, Cristina KL, Kabarowski JH, Witte ON, Xu Y (2001) Sphingosylphosphorylcholine and lysophosphatidylcholine are ligands for the G protein-coupled receptor GPR4. J Biol Chem 276:41325-41335. 